\title{
A efêmera e produtiva existência do Centro de Pesquisas Físicas da URGS
}

\author{
The ephemeral and productive existence of the URGS Center for Physical Research
}

\author{
Carlos Alberto dos Santos*
}

Departamento de Ciências Exatas e Naturais, Universidade Federal Rural do Semi-Árido, Mossoró, RN, Brasil

Recebido em 17 de Outubro, 2016. Aceito em 09 de Novembro, 2016.

\begin{abstract}
O Centro de Pesquisas Físicas da então denominada Universidade do Rio Grande do Sul (CPF-URGS) foi criado em 3 de setembro de 1953 e extinto em 9 de março de 1959. Ao longo desses cinco anos e seis meses, pesquisadores, técnicos e administradores do CPF constituíram uma comunidade harmoniosa, prestigiada pela administração superior da universidade e seriamente empenhada na construção de um ambiente de pesquisa científica e tecnológica de indiscutível bom nível. O objetivo deste trabalho é mostrar os elementos mais relevantes dessa trajetória, e como esse processo redundou em reconhecidos benefícios para o futuro do Instituto de Física, o órgão que sucedeu o CPF.

Palavras-chave: história da ciência, arquivo científico, instituição científica, Centro de Pesquisas Físicas, Universidade Federal do Rio Grande do Sul.
\end{abstract}

The Physics Research Center of the University of Rio Grande do Sul (CPF-URGS) was established on September 3, 1953 and terminated on March 9, 1959. During these five years and six months, researchers, technicians and adminsitrators of the CPF constituted a harmonious community, honored by the university administration and seriously committed to building a scientific and technological research environment of undisputed good level. The objective of this work is to show the most relevant elements of this trajectory, and how this process resulted in recognized benefits for the future of the Institute of Physics, the organization that succeeded the CPF.

Keywords: history of science, scientific archive, scientific institution, physics research center, Federal University of Rio Grande do Sul.

\section{Introdução}

No momento em que a Sociedade Brasileira de Física comemora seu primeiro cinquentenário, consideramos importante a divulgação de elementos formativos da nossa historiografia. Parte considerável da comunidade científica fundadora da SBF também teve participação relevante na criação de centros de pesquisa ao longo dos anos 1940-1960. Neste sentido, podemos destacar os seguintes eventos $[1,2]$ :

1. A contratação do físico alemão Bernhard Gross para trabalhar no Instituto Nacional de Tecnologia do Rio de Janeiro, onde desenvolveu importantes trabalhos sobre dielétricos, com a colaboração de Joaquim Costa Ribeiro. Em

*Endereço de correspondência: cas.ufrgs@gmail.com.
1943, esse cientista monta uma equipe no Departamento de Física da Faculdade Nacional de Filosofia da Universidade do Brasil para dar continuidade aos trabalhos iniciados com Bernhard Gross. Apesar da relevância de seus trabalhos, sobretudo para a história científica brasileira, eles não contribuíram para a formação de uma comunidade mais ampla no Rio de Janeiro.

2. Resultado mais favorável foi obtido no Departamento de Física da Faculdade de Filosofia, Ciências e Letras da Universidade de São Paulo. Com o físico russo Gleb Wataghin à frente, desde 1934, a USP conseguiu formar um ambiente de pesquisa que serviu de modelo para iniciativas similares. Seu rápido cresci- 
mento coincidiu com a criação de centros de pesquisa, organismos de apoio à pesquisa e associações científicas, entre os quais destacamos: o Centro Brasileiro de Pesquisas Físicas (CBPF), criado em 1949 e o Conselho Nacional de Pesquisas (CNPq), em 1951.

No bojo desse movimento, é criado, em 1953, o Centro de Pesquisas Físicas da Universidade do Rio Grande do Sul (CPF-URGS) 1 , e a exemplo das instituições de pesquisa mencionadas, ele tem na Faculdade de Filosofia (FF) sua alma mater. O funcionamento dos cursos de Matemática, Física, Química e História Natural da FF da Universidade de Porto Alegre foram autorizados em 1942, sendo o ano seguinte a vez da autorização dos cursos de Filosofia, Geografia e História, Letras Clássicas, Letras Neolatinas, Letras Anglo-germânicas, Pedagogia e Didática [3]. Em 1949, quando a universidade já tinha alterado o nome para Universidade do Rio Grande do Sul, Antônio Estevam Pinheiro Cabral obteve a primeira licenciatura em física da universidade [4].

Logo após a conclusão de sua Licenciatura, Cabral foi fazer um estágio com César Lattes, no Centro Brasileiro de Pesquisas Físicas (CBPF). A ideia era concluir o Doutorado em Física na Faculdade Nacional de Filosofia, mas o projeto foi interrompido no final de 1951, quando ele foi convidado a assumir a Cátedra de Mecânica Racional, Mecânica Celeste e Física Matemática, que se encontrava vaga na FF-URGS. Aceitou o convite com a condição de que fosse criado na URGS um centro de pesquisas similar ao CBPF.

Em setembro de 1952, o reitor Elyseu Paglioli nomeou uma comissão para o planejamento da instalação do Centro de Pesquisas Físicas [4], cujo relatório foi encaminhado ao Reitor em 27 de janeiro de 1953. Em 3 de setembro do mesmo ano era criado o CPF, órgão de natureza científica, autônomo e diretamente subordinado à Reitoria.

No dia 25 de março de 1959 realizava-se a última reunião do Conselho Deliberativo do CPF, 5 anos e 6 meses depois da criação. No dia 9 anterior havia sido criado o Instituto de Física da URGS, para onde foram transferidos os bens materiais e o pessoal técnico-científico do CPF.

\footnotetext{
${ }^{1}$ Embora federalizada em 1950, a Universidade do Rio Grande do Sul só adotou a denominação Universidade Federal do Rio Grande do Sul (UFRGS) no anos 1960.
}

O relato a seguir mostra que a breve existência do CPF é, em boa medida, responsável pelo sucesso alcançado pelo Instituto de Física durante esses 50 anos de vida. Embora não tenha produzido pesquisa científica relevante, durante sua curta existência o CPF desempenhou um papel importantíssimo no estabelecimento de uma cultura acadêmica e na preparação de infraestrutura para o desenvolvimento de pesquisa experimental e tecnológica. Quando, em dezembro de 1959 decidiu-se que o IF investiria em física experimental, todo o trabalho de base realizado no $\mathrm{CPF}$ foi de inestimável valor.

\section{Fontes primárias}

Em seu trabalho sobre os acervos documentais da UFRGS, Weber et al. [5] consideram dois indicadores: conservação e organização dos documentos. Para avaliar a situação dos acervos das 28 unidades visitadas, as autoras utilizaram uma escala de Likert com cinco itens: ótima, boa, regular, ruim, péssima. Em ambos os indicadores, a situação do Instituto de Física (IF) é tida como ruim. Por outro lado, hoje sabemos que se trata de um rico acervo, e temos a felicidade de verificar o senso de responsabilidade pela sua preservação, demonstrado por todos que anteriormente exerceram cargos administrativos no CPF e no IF2,

Para a realização desse trabalho utilizamos as seguintes fontes primárias:

1. Livro de Atas do Conselho Deliberativo do $\mathrm{CPF}[6]$.

2. Livro de Atas do Conselho Técnico Científico do $\mathrm{CPF}$ [7].

3. Correspondências e documentos diversos elaborados no período 1953-1959.

4. Acervo iconográfico do $\mathrm{CPF}$, sob a guarda do IF.

5. Relatório do Instituto de Física, para o exercício de 1969, apresentado pelo seu Diretor, David Mesquita da Cunha, no qual é apresentado um detalhado histórico do CPF, contendo também o plano de trabalho elaborado pela Comissão de planejamento da instalação do Centro de

\footnotetext{
${ }^{2}$ Os documentos utilizados como fontes primárias neste trabalho, não foram objeto de tratamento arquivístico sistemático. Eles encontram-se no "arquivo morto" do IF-UFRGS, na forma como foram arquivados ao longo dos anos.
} 
Pesquisas Físicas, e apresentado à Reitoria em 27 de janeiro de 1953 [8].

6. Depoimentos de três professores que participaram da criação do CPF e do IF, cujas carreiras acadêmicas serão brevemente descritas.

\section{Darcy Dillenburg}

Como estudante de Física na FF foi secretário ad hoc da Comissão de planejamento da instalação do CPF. Logo depois da criação do CPF, foi contratado como Auxiliar Técnico, antes da conclusão do Bacharelado. Ao se formar é promovido a $3^{\circ}$ Auxiliar de Pesquisas. Foi Chefe da Divisão de Ensino e da Divisão de Física Teórica do CPF. Aprovado em concurso público, ocupou a Cátedra de Física Geral e Experimental da FF. Participou do grupo de fundadores do Instituto de Física (IF). Com a extinção das Cátedras, foi enquadrado como Professor Titular. Ocupou vários cargos administrativos, entre os quais: Diretor do IF, Pró-Reitor de Graduação, Diretor de Avaliação da CAPES. Em 2004 a UFRGS concedeu-lhe o título de Professor Emérito.

\section{Gerhard Jacob}

Foi Chefe da Divisão de Física Teórica do CPF. Aprovado em concurso público, ocupou a Cátedra de Física Teórica e Física Superior. Participou do grupo de fundadores do IF. Com a extinção das Cátedras, foi enquadrado como Professor Titular. Ocupou vários cargos administrativos, entre os quais: Diretor do IF, Pró-Reitor de Pesquisa, de Planejamento, Vice-Reitor e Reitor, todos na Universidade Federal do Rio Grande do Sul, Presidente do Conselho Nacional de Desenvolvimento Científico e Tecnológico (CNPq), Pró-Reitor de Pesquisa e Pós-Graduação da Universidade Estadual do Rio Grande do Sul. É Pesquisador Emérito do CNPq e Grão-Cruz da Ordem Nacional do Mérito Científico.

\section{Paulo Pedro Petry}

Foi Chefe da Divisão de Eletrônica do CPF. Aprovado em concurso público, ocupou a Cátedra de Eletrotécnica Geral da Escola de Engenharia da UFRGS. Com a extinção das Cátedras, foi enquadrado como Professor Titular. Exerceu em várias oportunidades o cargo de Diretor do IF, em caráter pro tempore.

\section{Atos legais}

Decisão do Conselho Universitário, em 27/08/53, cria o Centro de Pesquisas Físicas e aprova seu Regimento, de conformidade com o Processo 3365/53, da Reitoria e Pareceres 55/53 (Comissão de Ensino e Recurso), 66/53 (Comissão de Legislação e Regimentos), 71/53 (Comissão de Orçamento e Regência Patrimonial).

Portaria 581, de 3/9/1953, formaliza a Decisão do Consun, criando o Centro de Pesquisas Físicas, órgão de natureza científica, autônomo e diretamente subordinado à Reitoria, regendo-se pelo regulamento aprovado na mesma oportunidade.

\section{Uma gestão bem sucedida}

Não temos conhecimento de registros das tratativas iniciais para a criação do $\mathrm{CPF}$, a não ser daqueles colhidos em depoimentos das nossas fontes (Darcy Dillenburg, Gerhard Jacob e Paulo Pedro Petry). Ao que tudo indica, a ideia surgiu por ocasião do convite feito a Antônio Estevam Pinheiro Cabral, para que ele ocupasse a Cátedra de Mecânica Racional, Mecânica Celeste e Física Matemática. À primeira vista isso parece ter sido simples, mas, na primeira ata do Conselho Deliberativo (CD) do CPF, realizada em 10 de setembro de 1953, consta que o Diretor Executivo do Centro, Luiz Pilla, "traça rápido esbôço $[s i c]$ histórico das gestões que culminaram com a resolução do Conselho Universitário". Infelizmente esse esboço histórico não foi transcrito na ata, mas a simples referência sugere que o processo não transcorreu com a simplicidade que se supunha.

Quaisquer que tenham sido as tratativas, o fato relevante é que o CPF surgiu com a aceitação explícita das principais lideranças universitárias da URGS. Apesar disso, os recursos financeiros foram inicialmente minguados [8]:

É válido registrar, como explicação para os minguados recursos disponíveis pelo Centro, em qualquer época, que não havia, então, na Universidade do Rio Grande do Sul, tradição em pesquisa científica, tal como se deve entendê-la, faltando, pois, a mentalidade própria e o "esprit du corpe", essenciais à meta programada, qualquer medida que trouxesse a idéia de pesquisa, certamente 
dava lugar a uma euforia generalizada, mas logo abafada pelo esquecimento e desinterêsse.

A composição do CD sinaliza bem o apoio institucional à criação do CPF. O Diretor Executivo, Luiz Pilla, era Catedrático de Físico-Química e Química Superior, da FF e de Físico-Química da Escola de Engenharia (EE). Todos os membros do Conselho eram destacados professores da FF e da EE. Álvaro Magalhães, Catedrático de História e Filosofia da Educação da FF e de Física Geral e Experimental II da EE, foi Diretor da FF, de 1946 a 1949. Ary Nunes Tietböhl, Catedrático de Análise Matemática e Análise Superior da FF e de Cálculo Diferencial e Integral da Arquitetura, foi Diretor da FF, de 1963 a 1966. Cayoby Vieira de Oliveira, Catedrático de Complementos de Matemática da FF, a partir de 1958. João Francisco Simões da Cunha, Catedrático de Física Teórica e Física Superior da FF e Assistente da Cadeira de Física Geral e Experimental II da EE. Em dezembro de 1953, Luiz Pilla é nomeado Diretor da FF e Ary Nunes Tietböhl é nomeado Diretor Executivo do Centro.

Além do Diretor Executivo, o CPF tinha um Diretor Científico, escolhido pelo $\mathrm{CD}$. Na primeira reunião, foi eleito, por unanimidade, Antônio Estevam Pinheiro Cabral. Como o nome sugere, ao Diretor Científico cabia a condução das atividades científicas, a participação no CD e a presidência do Conselho Técnico Científico, instalado em 18 de maio de 1954, e tendo como membros os chefes das divisões: Eletrônica, Matemática, Radioquímica, Ensino, e Emulsões Nucleares e Microscopia.

Depreende-se daí que as atividades do Centro seriam desenvolvidas pelas divisões relacionadas acima, uma estrutura muito similar àquela vigente no CBPF $[2,9]$. Mas, seis meses antes, na segunda reunião do $\mathrm{CD}(3 / 10 / 53)$, Cabral informara a estrutura planejada com seis Divisões: Alto Vácuo, Eletrônica, Emulsões Nucleares e Microscopia, Física Teórica, Matemática e Radioquímica.

Vejamos as razões pelas quais a estrutura inicialmente prevista difere daquela apresentada na ata da primeira reunião do Conselho Técnico-Científico (CTC). Por decisão do CD, cada divisão seria chefiada por alguém capaz de orientar pesquisas naquela área do conhecimento. Tentou-se, em vão, contratar Helmut Schwarz ${ }^{3}$ para a Divisão de Alto Vácuo,

${ }^{3}$ Perito alemão em tecnologia de alto vácuo. Trabalhava no CBPF. e não conseguindo outro profissional com o perfil adequado, as atividades dessa área passaram para a Divisão de Eletrônica. A Divisão de Ensino foi criada na reunião do CD, em 6 de abril de 1954. Nessa mesma reunião do CD, discute-se a admissão de Gerhard Jacob na Divisão de Física Teórica. Recémgraduado em Física (Bacharelado e Licenciatura) e Matemática (Bacharelado), Gerhard era Instrutor de Ensino Superior da Cátedra de Física Teórica e Superior ${ }^{4}$ Apesar do seu reconhecido potencial para a carreira acadêmica, sua admissão teve oposição enfática do seu superior hierárquico, o catedrático João Francisco Simões da Cunha, que afirmou não estar ainda preparado o jovem promissor para chefiar a Divisão de Física Teórica. Ficou registrado em ata, a sugestão de Pilla, Diretor da FF e membro do $\mathrm{CD}$, quanto à necessidade da contratação urgente de um pesquisador para chefiar a Divisão de Física Teórica.

Na reunião de 17 de junho de 1955, o CD atende sugestão do prof. Simões e admite o ingresso de Gerhard na Divisão de Física Teórica, como $3^{\circ}$ Auxiliar de Pesquisa. Em abril de 1958, Gerhard é nomeado Chefe da Divisão de Ensino e Darcy Dillenburg assume a chefia da Divisão de Física Teórica. Essas nomeações ocorreram, em parte, porque os dois professores haviam feito cursos de especialização na USP e estavam em vias de ingressar no Doutorado, quando foram convidados para retornar à URGS e iniciar o processo de criação do Instituto de Física, o órgão que sucedeu o CPF. Estavam, portanto, com a formação acadêmica bem encaminhada.

Em 7 de dezembro de 1954, o regimento do Centro foi alterado. Os cargos de Diretor Executivo e Diretor Científico foram extintos, passando o Centro a ter um único Diretor, a ser escolhido, pelo Reitor, de uma lista tríplice eleita pelo $\mathrm{CD}$, com mandato de 3 anos, podendo ser reconduzido. O Diretor passava a ser membro do Conselho Universitário. O CD, sob a presidência do Diretor, passava a ter a seguinte composição: três representantes da FF, eleitos pelos titulares dos departamentos de Física, Matemática e Química, e dois representantes da Escola de Engenharia. Três meses depois, na reunião de 26 de março do ano seguinte, o CD elege a lista tríplice para Diretor: Ary Nunes Tietböhl, Antônio Estevam Pinheiro Cabral e João Francisco Simões da Cunha.

\footnotetext{
${ }^{4}$ Cargo similar ao atual Professor Auxiliar. Na época atuava como assistente do Catedrático.
} 
Tietböhl, nomeado pelo Reitor, ocupou o cargo até a extinção do CPF.

As atas do CTC e do CD sugerem que os administradores do CPF empenharam-se para a contratação de pesquisadores qualificados para liderar pesquisas em Física Nuclear, a área de atuação escolhida. Fizeram muitos contatos, mas não tiveram sucesso nesse particular. Por outro lado, investiram tudo o que puderam no desenvolvimento da Divisão de Eletrônica. Examinado agora, em retrospectiva, não podemos deixar de apreciar o acerto administrativo. Também é notável a obediência dos administradores do CPF aos princípios básicos descritos no plano de trabalho apresentado pela Comissão de planejamento do Centro, em janeiro de 1953. Alguns pontos deste plano são apresentados a seguir [4].

\section{Plano de Trabalho inicial}

Em menos de quatro meses, a Comissão de planejamento do CPF produziu um relatório, que eles denominaram plano de trabalho, com tal nível de detalhamento que deve ter sido o resultado de reflexões anteriores à sua designação. Isso deve ter ocorrido com a chegada de Cabral no início do ano. Ao tratar das razões para a criação do Centro, a Comissão afirma que a "Universidade do Rio Grande do Sul, empenhada no desenvolvimento da pesquisa científica (...) decidiu promover pesquisas no setor da Física Moderna, que a capacitem a colocar-se entre as instituições do país que hoje formam a vanguarda com respeito ao vulto dessas pesquisas." Mais adiante, indicam o foco do projeto quando sugerem a "necessidade da intensificação das pesquisas atômicas no país".

Sobre as pesquisas em Física no Brasil, o documento se restringe às iniciativas das Faculdades de Filosofia do Rio de Janeiro e de São Paulo, salientando a participação de destacados físicos estrangeiros. São mencionados o CBPF, o laboratório de raios cósmicos em Chacaltaya, Bolívia, coordenado por César Lattes, o projeto de construção do sincrocíclotron, no Rio de Janeiro, o Betatron e o Gerador Van der Graaf em São Paulo. Essas referências indicam claramente os modelos a seguir. Não custa lembrar que este é o período da Guerra Fria, quando predominava a corrida mundial pelo domínio da tecnologia nuclear [9-13]. Do contexto histórico nos finais dos anos 1940 e início dos anos 1950, vale destacar o imbróglio em que se meteu o Brasil, por intermédio de diferentes autoridades, envolvendo contatos e contratos com os EUA, a França e a Alemanha Ocidental. Com os EUA, a venda de areia monazítica, rica em tório, e a compra de aceleradores de partículas. Na França, foi celebrado um contrato com a Societé des Produits Chimiques des Terres Rares para implantação de um complexo industrial, em Poços de Caldas (MG), para produção de sais de urânio metálico nuclearmente puro. Com a Alemanha Ocidental, o caso mais grave, o $\mathrm{CNPq}$ contratou a construção de uma planta de ultracentrifugação, destinada à separação isotópica do hexafluoreto de urânio. Em 1954, "há 24 horas da saída do material pelo porto de Hamburgo e por ordem do Alto Comissário de Ocupação da Alemanha (...) o embarque foi negado e todo o material apreendido" [14]. Não há, nos arquivos do $\mathrm{CPF}$, qualquer referência a esses eventos, embora na perspectiva história eles estejam fortemente correlacionados com a criação do $\mathrm{CPF}$ e com as linhas de pesquisa que ali se pretendia implementar.

Ao final da seção sobre as pesquisas em Física no Brasil a Comissão afirma: "Ao decidirmos iniciar nesta Universidade um centro ativo de pesquisas em Física, temos como certo podermos contribuir em futuro próximo com uma parcela de físicos, técnicos e pesquisadores, para os grandes empreendimentos em perspectiva no País." [8]. De fato, das bancadas do laboratório de eletrônica do CPF e da oficina que o sucedeu no IF, partiram alguns engenheiros para a criação, por exemplo, da Edisa, a fábrica de computadores que originou o polo de informática do RS, da Parks, da Digitel e da Altus, precursoras da indústria eletrônica no RS. Outros partiram para a criação do Curso de Pós-Graduação em Ciência da Computação, a semente do Instituto de Informática da UFRGS. Inúmeros estagiários de engenharia no CPF e no IF montaram pequenas fábricas de produtos eletro-eletrônicos. Também são incontáveis os bacharéis em Física que foram trabalhar na indústria.

A comissão foi criteriosa na realização da sua tarefa [8]:

Essa Comissão para o melhor desempenho de suas atribuições julgou conveniente pedir a colaboração do Centro Brasileiro de Pesquisas Físicas, convidando alguns de seus físicos a virem a esta Capital. Com a interferência do Sr. Diretor da Faculdade de Filosofia [Bernardo Geisel] e o apôio decidido do Conselho Nacional 
de Pesquisas, contamos, em novembro último, com a presença do Professor Dr. Helmut Schwartz em Pôrto Alegre. Além de um ciclo de palestras que o referido professor realizou no Instituto de Física [Órgão da Escola de Engenharia. Não confundir com o IF, que seria criado em 1959], prestou a mais franca colaboração, discutindo o plano de trabalho para o novo Centro. A Comissão aguarda para os próximos meses a vinda dos professores Hugo Camerini e Gerard Hepp cujas atividades no Centro Brasileiro de Pesquisas Físicas não permitiram ainda sua viagem a Pôrto Alegre.

Sobre o plano de trabalho, constata-se a visão previdente daqueles gestores [8]:

Tendo em vista também as dificuldades em contar desde logo com pessoal especializado em número suficiente, cumpre também desenvolver, desde logo, tarefas que, além de básicas, venham proporcionar um útil treinamento aos que desejam participar das pesquisas.

A Divisão de Eletrônica foi a única que apresentou desenvolvimento notável e extremamente útil para as pesquisas que seriam futuramente implementadas no IF. Embora não tenham tido sucesso na contratação de um pesquisador com formação completa para dirigir a seção de alto vácuo, estudos foram implementados nessa área, e a equipe do CPF terminou dominando aspectos importantes dessa tecnologia.

No que se refere ao pessoal técnico e científico, o planejamento também é notável [8]:

Espera a Universidade contar desde logo com a colaboração de seus professores, assistentes e instrutores cujas cadeiras visem a especialização dos diversos domínios da Física. Os egressos desta e de outras Universidades, bem assim indivíduos de reconhecida capacidade, desde que demonstrem aptidão para a pesquisa poderão ser aproveitados, de acordo com as necessidades e possibilidade do Centro. Está em cogitação nesta Universidade a instituição do regime de tempo integral para os que se dedicam à pesquisa.
Pensa-se também encaminhar, anualmente, bolsistas a outros centros de pesquisa, nacionais e estrangeiros.

Já foi assentada, junto à Direção do Centro Brasileiro de Pesquisas Física, a ida de dois técnicos em eletricidade, formados por uma Escola Técnica de nível médio, para especializarem-se, durante alguns meses, nos laboratórios de Eletrônica daquele Centro, na montagem de circuitos.

Julgamos imprescindível a vinda de, pelo menos, dois especialistas, um em Eletrônica e outro em Descarga nos Gases. Já há entendimento no sentido de conseguir a participação de dois físicos estrangeiros, que viriam especialmente contratados para esta Universidade.

\section{A Divisão de Eletrônica}

Na consolidação da estrutura administrativa do $\mathrm{CPF}$, a Divisão de Eletrônica (DE) englobou a Divisão de Alto Vácuo e a Oficina Mecânica. Sob o estrito ponto de vista da pesquisa científica, de todas as divisões, a DE foi a mais produtiva. As Divisões de Ensino e Matemática cuidavam da organização de cursos e seminários, enquanto a Divisão de Física Teórica só teve seu primeiro elemento, Gerhard Jacob, em junho de 1955. Pela falta de um pesquisador com formação completa, esta Divisão também atuou essencialmente na organização de cursos e seminários. Todavia, em uma perspectiva mais ampla, essas atividades se mostraram importantíssimas para a formação do espírito acadêmico que terminou se consolidando ao longo dos anos seguintes.

Não há dúvida de que o sucesso da DE pode ser atribuído à competência e dedicação de dois engenheiros: Gerard Hepp e Paulo Pedro Petry. O primeiro, engenheiro eletrônico da Philips, perito em detetores nucleares, chegou ao Brasil em 1951 para realizar uma missão da Unesco junto ao CBPF. Em 18 de março de 1954, ele se transferiu para o CPF. Na chegada de Hepp, o jornal Folha da Tarde publica uma matéria (Figura 1), na qual ele aparece ao lado de Petry, sobre o qual consta na reportagem a informação de que acabara de instalar os primeiros transmissores da Rádio da Universidade. Consta 

a nova geração de físicos eletrônicos O professor Gerard Hepp contratado pela Universidade do Rio Grande do Suil, deverá orientar os trabalhos de pe squisas eletronicas neste novo centro de investigações cienti ficas do nosso Estado



Ao lado do dr. Paulo Pedro Petry, o professor Gerard Hepp, físico holandês especialista em eletrônica, conversa com 0 repórter, entre uma porçáo de aparêlhos e fios e baterias e outras coisas que servirão para ensinar e aprender neste misterioso campo da eletrônica.
Hoje conversamos com o professor Gerard Hepp. Depois de realizar uma missão especial da Unesco no Rio de Janeiro junto ao Centro Brasileiro de Pesquisas Físicas, esse cientista espécializado em assuntos de eletronica aceitou um convite p. ra or:e: ar o início das atividades do Centro de Pesquisas da Universidade do Rio Grande do Sul.

O professor Hepp chegou ao Brasil em 1951 e dispõe de mais de um ano para permanecer entre nós. Muito embora não nos tivesse esboçado com precisão os limites de sua atividade entre nús, informou-nos o cientista que deverá dedicar boa parte de sua permanencia aqui, no preparo de um ambiente satísfatório à realizacão do programa de ação do Centro de Pesquisas Físicas e Matematicas.

\section{ESTUDOS DE FrSICA}

\section{NUCLE:R}

Conhecedores da importancia do continua na 8.a página)
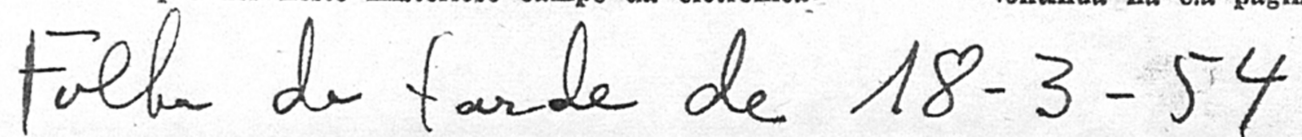

Figura 1: Extrato da reportagem da Folha da Tarde. A partir da esquerda: Paulo Pedro Petry, Gerard Hepp e o repórter da Folha da Tarde.

também a informação de que o CPF estava oferecendo o Curso de Introdução à Eletrônica Aplicada, ministrado por Petry.

Sobre a importância de Gerard Hepp, Darcy Dillenburg fez a seguinte declaração [15]:

\section{(...) juntou um grupo de profissionais} para trabalhar com ele, aprendendo técnicas modernas de pesquisa.

O laboratório [de eletrônica], depois dirigido pelo professor Paulo Pedro Petry, foi um instrumento importante quando começaram as atividades de pesquisa na UFRGS. Foi implantado também um laboratório de radioquímica que teve a cooperação de professores do Departamento de química da Faculdade de Filosofia, onde estava também o professor Luiz Pilla e outros, que colaboraram no manuseio na química de materiais radioativos, o material que se ia trabalhar no Centro.

Além disso, se instalou uma excelente oficina mecânica de precisão, que ao longo dos anos construiu extraordinários equipamentos ou componentes de equipamentos que precisavam ser adaptados aos aparelhos existentes ou para substituir peças. Foi um elemento fundamental nas etapas seguintes. 
Na comemoração do primeiro aniversário do CPF, em 3 de setembro de 1954, menos de seis meses após a chegada de Hepp, o Centro exibiu equipamentos em avançado estágio de construção na DE. Digno de nota é o microscópio óptico com imagem projetada em um cinescópio. Eles o denominaram telemicroscópio. O equipamento funcionava como um circuito fechado de TV. Não há registro escrito, mas em depoimento ao autor, Paulo Pedro Petry informou que ele foi testado em exames oftalmológicos. Duas fotografias ilustram o andamento dos trabalhos. Na primeira (Figura 2a), durante a visita do Reitor por ocasião do primeiro aniversário do CPF, observa-se a parte do equipamento correspondente à transmissão da imagem para o cinescópio. Na segunda fotografia (Figura 2b), obtida entre 1954 e 1955, vê-se o equipamento completo. Outro equipamento que merece destaque é um computador analógico montado no CPF (Figura 3). Esses equipamentos, com sofisticados recursos tecnológicos, serviram para o treinamento de inúmeros estagiários de engenharia, e para estabelecer uma escola de desenvolvimento tecnológico. A ideia foi bem tratada e influenciou marcadamente as primeiras gerações de físicos formados no IF. Nos anos 1970, o percentual de equipamentos desenvolvidos localmente, em relação aos importados era claramente maior no IF do que em outros centros de pesquisa nacionais.

O prestígio da DE logo ultrapassou a porta do CPF e até mesmo os muros da Universidade. Para a Varig, foi desenvolvido um sistema de alto vácuo para calibração de altímetros. Nos arquivos preservados no IF, foram encontradas inúmeras solicitações de outras faculdades e de órgãos externos à URGS, para o conserto de diferentes equipamentos eletroeletrônicos. Entre essas solicitações, ocupa posição de destaque aquela referente ao sincrocíclotron do CNPq, apresentada abaixo.

\section{Intercâmbio acadêmico}

Os membros do CPF estabeleceram muitos contatos com colegas de outras instituições, quer seja na busca de auxílio para a identificação de pesquisadores qualificados para liderar o início das pesquisas, ou para a discussão de questões científicas pertinentes aos projetos do Centro. Tendo o início do Centro estreita relação com o CBPF, em função do vínculo entre Cabral e César Lattes, é natural que os primeiros consultores tenham vindo do Rio de
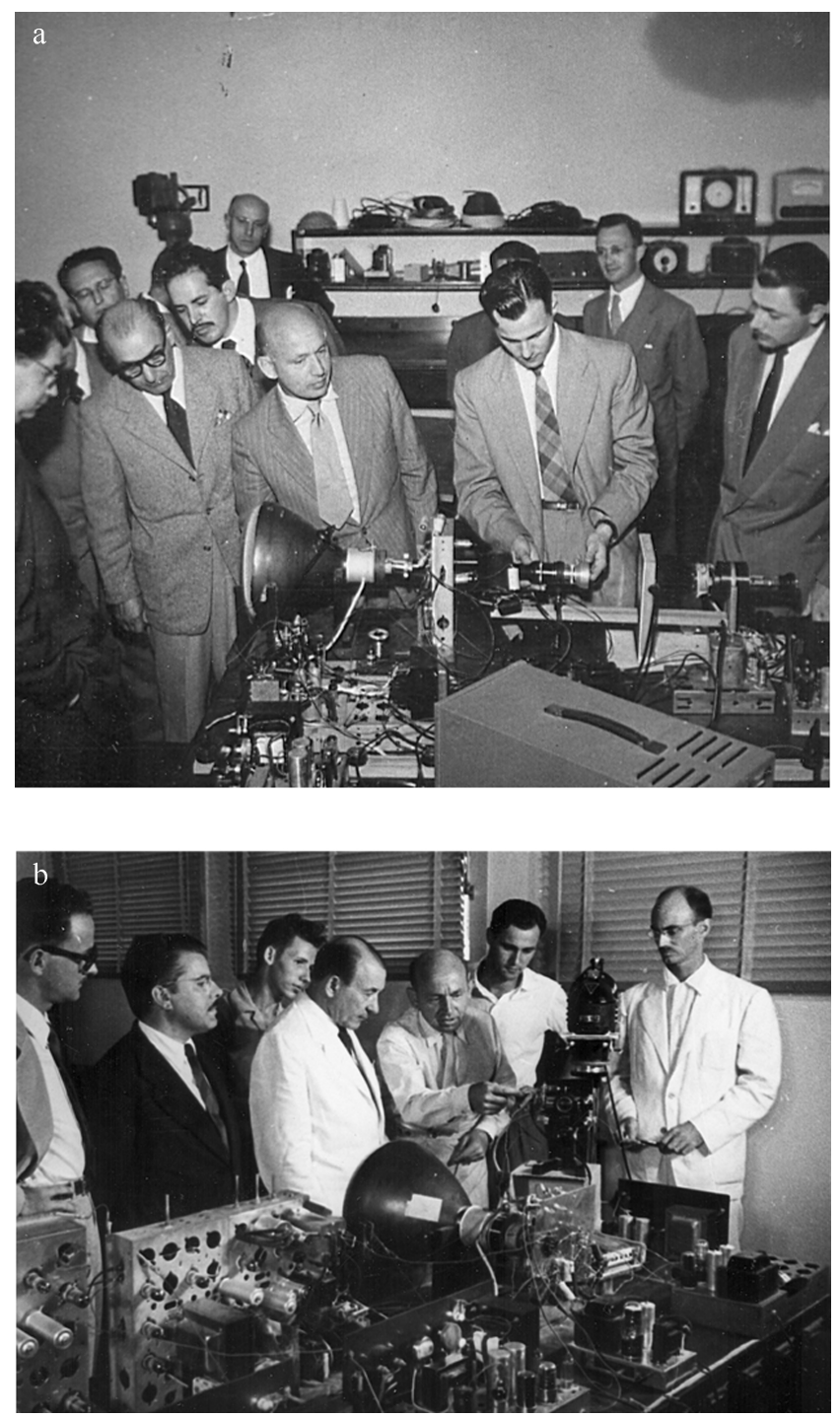

Figura 2: (a) - Visita do Reitor durante o primeiro aniversário do CPF. No primeiro plano, a partir da esquerda: Não identificado (de perfil), Elyseu Paglioli, Gerard Hepp, José Reinaldo Salvador e Antônio Bernardo João Batista Todesco. (b) - Visita do Reitor, entre 1954 e 1955. No primeiro plano, a partir da esquerda: Não identificado (de perfil), Ary Nunes Tietböhl, Elyseu Paglioli, Gerard Hepp e Paulo Pedro Petry.

Janeiro. Como se viu acima, o primeiro a visitar a URGS para discutir questões pertinentes ao CPF foi Helmut Schwartz, um especialista em alto vácuo. A visita ocorreu na fase de planejamento do Centro. A expectativa era que em seguida viessem Ugo Camerin:5 e Gerard Hepp. Este chegou ao CPF para ficar, em 1954, e Camerini só pôde visitar o Centro em outubro de 1956.

\footnotetext{
${ }^{5}$ Físico italiano, especialista em raios cósmicos
} 


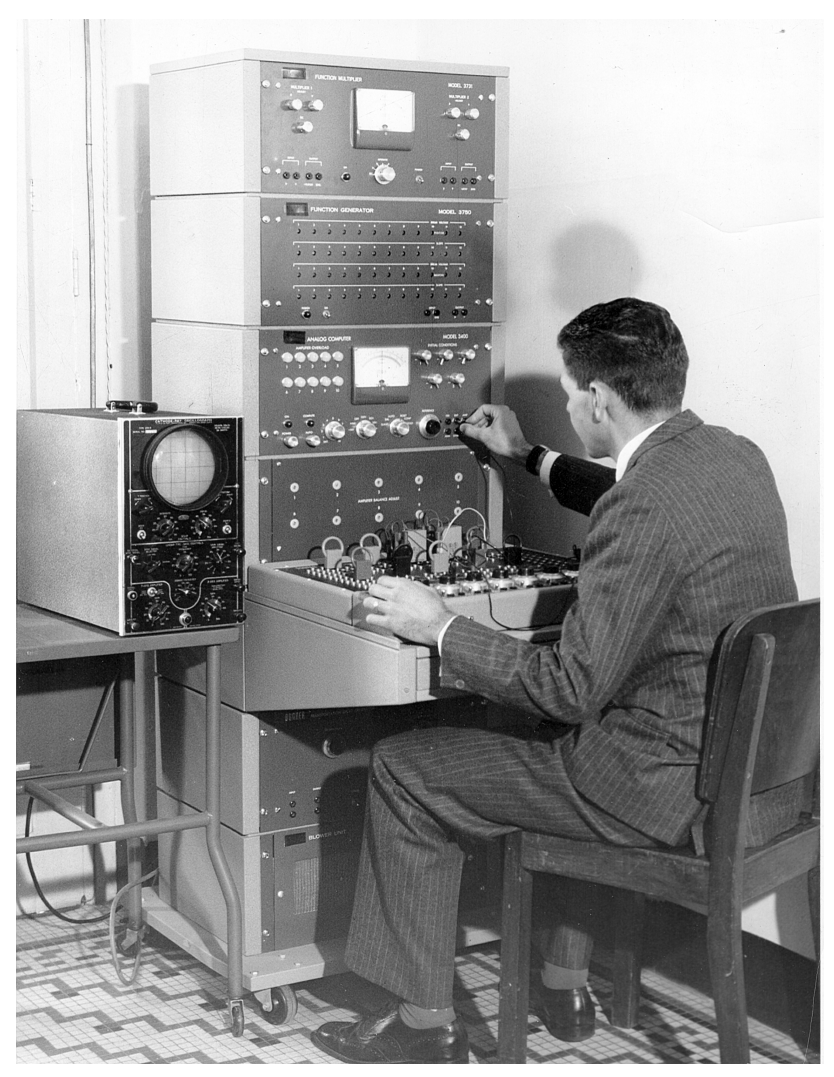

Figura 3: Estagiário manipulando o computador analógico montado no CPF.

Não se trata aqui de fazer uma análise pormenorizada da vasta correspondência arquivada no IF. O que se pretende é apenas dar uma ideia da relevância da rede de contatos mencionando a correspondência com destacadas personalidades da história científica brasileira, bem como de alguns estrangeiros igualmente notáveis. Nesse sentido, também cabe mencionar alguns visitantes importantes. Não mencionarei aqui a correspondência protocolar. Apenas aquela estritamente relacionada com a atividade científica será considerada.

Entre 23 de maio e 4 de junho de 1955, o físico argentino Jorge P. Staricco, professor da Universidade de Buenos Aires, ministrou cursos de Termodinâmica, Mecânica Quântica e Teoria da Relatividade. Logo depois, o CD decide convidá-lo para passar uma temporada de 3 meses, durante os quais ministraria cursos de maior duraçãd ${ }^{6}$ Na reunião do CTC, em 19 de agosto, Ary Tietböhl informa que Staricco não virá por causa da situação política na Argentina. Em novembro fica-se sabendo que ele havia sido nomeado Diretor do Ensino Secundário

\footnotetext{
${ }^{6}$ Havia na época a expectativa de que Jorge Staricco viesse coordenar a Divisão de Física Teórica.
}

da Argentina, razão pela qual não poderia aceitar o convite do CPF. Por indicação de José Leite Lopes e Leopoldo Nachbin, o CPF convidou Juan Jose Giambiagi para ministrar um seminário. Em 8 de novembro de 1955, Giambiagi faria a primeira de várias visitas à URGS: setembro de 1960; janeiro e dezembro de 1964; janeiro de 1968; e setembro de 1969.

Quanto a Jorge P. Staricco, há uma carta de Tietböhl (29 de dezembro de 1956), na qual ele se refere ao convite feito meses antes, para Staricco vir reger a cadeira de Física Geral Experimental, a partir de março de 1957, com as seguintes condições:

Contrato de um ano, renovável, e ven-
cimentos de Cr\$30.000,00 (trinta mil
cruzeiros) mensais, entrando a Universi-
dade com Cr $\$ 17.000,00$ (dezessete mil
cruzeiros), e estando os restantes Cr\$
$13.000,00$ (treze mil cruzeiros) a cargo
do Conselho Nacional de Pesquisas.

Não há registro da resposta de Staricco, mas é certo que ele esteve no CPF em 1957, ministrando um curso de Física Geral e Experimental, talvez de curta duração. Uma pequena brochura de sua autoria, intitulada "Notas de magnetismo eletromagnetismo" foi encontrada no arquivo do IF. Em 1958, ele ministrou a aula inaugural da FF, intitulada "Galileo e Einstein: duas épocas". Além disso, registros orais dão conta de que foi por sua sugestão que as práticas de laboratório foram introduzidas na cadeira de Física Geral e Experimental, sendo Fernando Cláudio Zawislak, a partir de 1958, o responsável pela inovaçãd7 Em 1961, Staricco permaneceu no IF de 5 de agosto a 31 de outubro, oportunidade em que ministrou cinco cursos versando desde Física Geral até Mecânica Quântica Avançada. A última visita de que se tem registro ocorreu em julho de 1964.

Darcy e Gerhard passaram janeiro e fevereiro de 1956 na USP, fazendo o Curso de Física de Reatores. Esse curso serviu para selecionar jovens pesquisadores para trabalhar no primeiro reator de pesquisas do Brasil, que entraria em funcionamento em setembro do ano seguinte. Os dois foram selecionados e voltaram a São Paulo em julho, ali permanecendo até fevereiro de 1958, entre o Instituto de Energia Atômica, a Faculdade de Filosofia da USP, no famoso endereço da rua Maria Antônia, 294, $4^{\circ}$. andar,

\footnotetext{
${ }^{7}$ Comunicação pessoal de Beatriz Maria Mikusinski Zawislak.
} 
e o ITA, em São José dos Campos. Essa foi a primeira oportunidade que tiveram para se inserir na comunidade científica externa e para iniciar contatos acadêmicos. No curso de férias oferecido no ITA conheceram Marcos Moshinsky. No ano seguinte Darcy foi convidado para trabalhar com Moshinsky durante alguns meses. Ao chegar na Cidade do México, soube da programação da Primeira Escola LatinoAmericana de Física, e providenciou que Gerhard fosse convidado para o evento, durante o qual conheceram Mael Melvin, físico da Universidade da Flórida, que juntamente com um colega estava interessado em passar uma temporada na América Latina. O colega era Theodor August Johannes Maris, um físico teórico com o perfil que eles buscavam desde a criação do CPF. Chegou em Porto Alegre em outubro de 1959, para nunca mais deixar a cidade, a não ser em missões científicas ou viagens de férias. Em 1990 a UFRGS outorgou-lhe o título de Professor Emérito.

Um contato duradouro, epistolar, foi de Darcy e Gerhard com Guido Beck. Entre 1958 e 1962 trocaram mais de 30 cartas, telegramas e cartões postais.

Além desses contatos mais prolongados, a simples menção dos visitantes e correspondentes ilustres mostra que o CPF fazia parte da rede científica da época. Por exemplo, há registros do contato feito por Darcy e Gerhard com Hideki Yukawa, Prêmio Nobel de Física de 1949. Dois colaboradores de Yukawa, Mituo Taketani e Yasuhisa Katayama, que estavam passando uma temporada no Instituto de Física Teórica de São Paulo, visitaram o CPF em novembro de 1958 (Figura 4).

Logo depois de ser designado diretor do setor de pesquisas matemáticas do $\mathrm{CNPq}$, Leopoldo Nachbin escreve para o diretor do CPF, orientando-o a solicitar recursos para a assinatura de periódicos de matemática, pois se sentia na "obrigação de estimular pedidos de auxílio das instituições dos estados onde existem possibilidades de se desenvolver núcleos matemáticos sérios".

Em 3 de janeiro de 1958, Gerard Hepp escreve para Roberto Salmeron: "Informado de que você está disposto a voltar ao Brasil, gostaria de dirigir sua atenção para o Centro de Pesquisas Físicas de Pôrto Alegre." Depois de descrever o CPF e esclarecer que "a atmosfera não é carregada como antigamente no C.B.P.F. Aqui há mais um espírito de amizade e cooperação", ele convida Salmeron para trabalhar no Centro. No mês seguinte Darcy



Figura 4: A partir da esquerda: a bibliotecária Frida Issler, o professor Mituo Taketani e a estudante de física Alice Maciel.

e Gerhard ratificam o convite feito por Hepp. No início de março, Salmeron responde, lamentando não poder atender o convite. A carta contém várias sugestões para a gestão de um centro de pesquisa de qualidade. Nas suas palavras, "são os pontos por onde eu começaria a pensar se tivesse aceito a direção do Instituto".

Em 10 de fevereiro de 1958, o presidente da Comissão Nacional de Energia Nuclear escreve para o diretor do CPF solicitando que este encaminhasse trabalhos que julgasse merecedores de apresentação na Segunda Conferência Internacional sobre Usos Pacíficos da Energia Atômica, que se realizaria em agosto daquele ano em Genebra. Um trabalho de Gerhard e outro de Darcy, Gerhard e Paulo Saraiva de Toledo foram apresentados na Conferência (Figura 5).

\section{O CPF e o sincrocíclotron do $\mathrm{CNPq}$}

Vários documentos mostram que a instalação de um acelerador de partículas no CPF foi uma ideia recorrente durante toda a sua existência. Um relato razoavelmente completo dessa história foi apresentado em artigo publicado na RBEF em 2013 [16]. 




THE $\mathrm{Be}^{9}(n, 2 n) \mathrm{Be}^{8}$ REACTION AND ITS INFLUENCE ON THE INFINITE MULTIPLICATION FACTOR FOR BERYLLIUM MODERATED HETEROCENEOUS THERMAL REACTORS

A REAÇÃO $\operatorname{Be}^{9}(n, 2 n) \mathrm{Be}^{8}$ E A SUA INFLUENCIA SÔBRE O FATOR DE MULTIPLICAÇÃO INFINITA EM REATORES TÉRMICOS HETEROGENEOS MODERADOS POR BERÍLIO

D. DILLENBURG, G. JACOB e P. S. TOLEDO

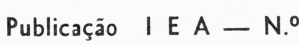

INSTITUTO DE ENERGIA ATOMICA Caixa Postal 11049 (Pinheiros) CIDADE UNIVERSITÁRIA "ARMANDO DE SALLES OLIVEIRA"
SÃO PAULO - BRASIL

Figura 5: Separata do artigo Darcy, Gerhard e Saraiva, publicado em: Proceedings of the Second United Nations Internacional Conference on the Peaceful Uses of Atomic Energy, 1958. v. 12. p. 607.

É difícil estabelecer um contexto fiel ao que hoje sabemos sobre os eventos históricos da época, apenas utilizando os registros mencionados acima. Não resta a menor dúvida de que Gerard Hepp estava extremamente motivado para construir um acelerador de partículas em Porto Alegre. Não tinha certeza que tipo de acelerador seria mais conveniente, até porque não havia físicos experimentais no $\mathrm{CPF}$ que pudessem colaborar no projeto, definindo linhas de pesquisa pertinentes. Por outro lado, determinados trechos das atas são enigmáticos. Um cenário consistente se descortina quando os registros são colocados ao lado de informações contidas no livro de Ana Maria Ribeiro de Andrade (1999). Há uma frase no livro que dá grande significado aos registros do CTC-CPF, sobretudo considerando-se que o CBPF era o modelo seguido pelo CPF: "Em 1950, porém, um cíclotron se destacava entre os equipamentos prioritários para a pesquisa no $\mathrm{CBPF}$, ao lado de uma encomenda feita à Philips holandesa de um acelerador de alta tensão" (p. 175). Convém lembrar que Gerard Hepp era engenheiro da Philips holandesa, e que viera para o $\mathrm{CBPF}$, com auxílio da Unesco para auxiliar na fabricação de pequenos detetores de radiação.

Objetivamente, a história do sincrocíclotron do $\mathrm{CNPq}$ se entrelaça com a do CPF a partir de uma correspondência enviada em 6 de outubro de 1956, pelo Reitor da URGS ao Cel. Aldo Vieira da Rosa, Presidente do CNPq:

Ciente de que êsse colendo Conselho está estudando o destino a ser dado ao "cíclotron" de 12" de sua propriedade, tenho a honra de transmitir a Vossa Excelência o interêsse e o empenho desta Universidade em contar com o aparêlho acelerador de partículas, a fim de destiná-lo ao Centro de Pesquisas Físicas (...).

É uma feliz coincidência que o "cíclotron" esteja disponível justamente no momento em que os integrantes científicos do nosso Centro de Pesquisas Físicas estudam a possibilidade de construir um aparêlho acelerador nesta Universidade, em local já existente não só na atual séde provisória como na definitiva, cuja pedra fundamental será lançada ainda êste ano.

Permito-me esclarecer, ainda, que esta Universidade, pelas verbas específicas do orçamento do nosso Centro, no exercício corrente, está apta a custear as despesas de desmontagem, transporte e instalações iniciais nas mesmas condições, no mínimo, das já existentes.

Como relatado por Santos [16], o CNPq decide, em 1957, prosseguir com a instalação do sincrocíclotron, mas, um ano depois convidou o CPF para revisar as instalações do equipamento e colocá-lo em funcionamento. A equipe coordenada por Hepp trabalhou no projeto a partir julho de 1958, mas uma série de eventos políticos resultaram no seu abandono em fevereiro de 1963. Em abril de 1998 o sincrocíclotron foi transferido do galpão no Morro de São João Baptista onde fora instalado, para o Museu de Astronomia e Ciências Afins [9]. 


\section{Fundamentos Físicos de Engenharia Nuclear}

Atento às possibilidades de financiamento de pesquisas por parte da Comissão Nacional de Energia Nuclear (CNEN) e de intercâmbio com o recémcriado Instituto de Energia Atômica (IEA) de São Paulo, Gerhard Jacob propõe, em reunião do CTC $(9 / 6 / 58)$, a oferta de um curso sobre reatores. Os melhores alunos receberiam bolsa para estagiar no IEA. No mês seguinte, exatamente no dia 9 de julho, Gerhard e Darcy Dillenburg visitaram o Almirante Otacílio Cunha, presidente da CNEN, com a proposta do curso, que já tinha a denominação como foi ofertado: Fundamentos Físicos de Engenharia Nuclear. O processo correu rápido. O presidente aceitou a ideia, os dois viajaram para São Paulo para acertar detalhes do intercâmbio com o IEA, e no dia 15 Darcy já escrevia para Ary Tietböhl, diretor do $\mathrm{CPF}$, dando as novidades. No momento em que escrevia a carta, Gerhard fazia o esboço do projeto que o $\mathrm{CPF}$ deveria enviar à $\mathrm{CNEN}$, orçado em Cr\$1.115.000,00 (um milhão e cento e quinze mil cruzeiros). Era uma boa soma de dinheiro, quase a metade do orçamento do Centro para o ano de 1959.

O curso foi realizado de 18 de agosto a 13 de novembro de 1958. As aulas teóricas foram ministradas por Darcy (Física de reatores) e Gerhard (Física nuclear), enquanto Antônio Bernardo João Batista Todesco ministrou as experimentais. Dos 34 inscritos, em sua grande maioria engenheiros, apenas 8 fizeram os exames finais, e 4 engenheiros obtiveram nota superior a 7, o mínimo para aprovação. Os aprovados realizaram um estágio de dois meses no IEA.

Com a extinção do CPF e a criação do Instituto de Física em março de 1959, o curso foi reformulado e, de 1962 a 1973 foi ofertado com a denominação Introdução à Energia Nuclear.

\section{Comentários finais}

No que se refere ao desenvolvimento de uma infraestrutura instrumental para a pesquisa em física experimental o $\mathrm{CPF}$ foi inegavelmente um grande sucesso. No entanto, pelo insucesso na contratação de físicos teóricos e experimentais com formação completa, não se chegou ao desenvolvimento de pesquisa científica autóctone. No entanto, com a breve orientação de Paulo Saraiva de Toledo, professor da
Faculdade de Filosofia, Ciências e Letras da USP, Darcy Dillenburg e Gerhard Jacob produziram dois trabalhos que foram selecionados para representar o Brasil na Segunda Conferência Internacional sobre Usos Pacíficos da Energia Atômica, realizada em Genebra em 1958:

1. Darcy Dillenburg, Gerhard Jacob and Paulo Saraiva de Toledo. The $\mathrm{Be}^{9}(\mathrm{n}, 2 \mathrm{n}) \mathrm{Be}^{8}$ Reaction and its Influence on the Infinite Multiplication Factor for Beryllium Moderated Hetergoeneous Thermal Reactors. Proceedings of the Second United Nations International Conference on the Peaceful Uses of Atomic Energy 12 (1958) 607.

2. Gerhard Jacob: On the Diffusion of Neutrons in Moderating and Multiplying Media with a Periodic Neutron Source. Proceedings of the Second United Nations International Conference on the Peaceful Uses of Atomic Energy 12 (1958) 590.

Esses trabalhos foram traduzidos e publicados nos Anais da Academia Brasileira de Ciências, no volume 30 (1958), páginas 147 e 295, respectivamente.

Não cabe aqui especular sobre o quê teria sido da pesquisa em física na UFRGS se o acelerador do CNPq fosse cedido, ou se os recursos prometidos pelo $\mathrm{CNPq}$ tivessem sido transferidos para a construção de um acelerador no CPF ou no IF. De tudo o que sabemos, o fato relevante nessa história é que o CPF formou uma escola preparada para o desenvolvimento de pesquisa em física experimental e em tecnologia. A infraestrutura resultante dessa atividade foi de inestimável valor para o desenvolvimento da física experimental no Instituto de Física a partir de 1960.

Embora tenha adotado um sistema organizacional muito bem estruturado, o CPF foi vítima de eventos circunstanciais muito comuns na história da ciência. Esses eventos são determinados pelos interesses acadêmicos e aptidões profissionais de seus líderes e a evolução histórica do órgão depende do sucesso desses líderes. Conforme relatado neste trabalho, o CPF teve a participação direta de uma dezena de professores, mas apenas quatro lideraram substancialmente os trabalhos de pesquisa e definiram a formatação acadêmica do Instituto de Física, o sucedâneo do CPF. O professor Antônio Cabral, o inspirador do $\mathrm{CPF}$, teve problemas de saúde e não pôde dar prosseguimento a seus projetos de pesquisa 
experimental. Nessa área, o CPF contava com os engenheiro Gerard Hepp e Paulo Pedro Petry. O primeiro tinha evidente ambição de instalar uma linha de pesquisa experimental em aceleradores nucleares, mas o professor Petry era mais vocacionado para a instrumentação eletrônica como suporte da pesquisa experimental em qualquer área. Com as dificuldades em obter recursos para seus projetos de pesquisa, e a frustração com o sincrocíclotron do CNPq [16], Hepp retorna para a Holanda. Foram essas circunstâncias que determinaram o caráter auxiliar da Divisão de Eletrônica e a inexistência de uma linha de pesquisa experimental em física no CPF.

Os outros dois professores que exerceram lideranças essenciais na evolução do $\mathrm{CPF}$ e criação do IF, Darcy Dillenburg e Gerhard Jacob não tinham a menor aptidão para o trabalho experimental. Portanto, seus esforços acadêmicos progrediram em paralelo à tentativa de Hepp em construir um acelerador de partículas. $\mathrm{O}$ insucesso deste, definiu o perfil de pesquisa do $\mathrm{CPF}$, ou seja física nuclear teórica, mas na transição CPF-IF, decidiu-se que o IF investiria em pesquisa experimental na área de correlação angular de raios gama [4].

Em suma, o CPF foi constituído por professores catedráticos da Faculdade de Filosofia e da Escola de Engenharia. Entre esses catedráticos, nenhum tinha doutorado ou tese de cátedra em física. Todos os que dedicavam-se à pesquisa em física estavam em seus inícios de carreira. Darcy Dillenburg e Gerhard Jacob foram contratados pelo CPF logo depois da conclusão de suas licenciaturas, e ainda antes de suas defesas de tese de cátedra foram contratados como catedráticos na Faculdade de Filosofia [4]. Ambos defenderam suas teses depois da criação do IF. Portanto, todos os físicos que trabalharam no CPF, participaram da criação do IF e obtiveram suas titulações após a transição CPF-IF, a saber:

1. Darcy Dillenburg - Tese de Cátedra, Faculdade de Filosofia (UFRGS), 1960.

2. Gerhard Jacob - Tese de Cátedra, Faculdade de Filosofia (UFRGS), 1964.

3. Fernando Cláudio Zawislak - Doutorado, IFUFRGS, 1967.

4. Victoria Elnecave Herscovitz - Doutorado, IFUFRGS, 1969

5. Alice Maciel - Doutorado, IF-UFRGS, 1970.

\section{Referências}

[1] M.G. Ferri e S. Motoyama (orgs.), A História das Ciências no Brasil, v. 1 (Edusp, São Paulo, 1979).

[2] J.L. Lopes, Uma História da Fúsica no Brasil (Livraria da Física, São Paulo, 2004).

[3] L.F. Hessel e E.D.M. Moreira, Faculdade de Filosofia. 25 anos de Atividade (1942-1967) (Editora da UFRGS, Porto Alegre, 1967).

[4] C.A. dos Santos (org.), Instituto de Física da UFRGS. 50 Anos de Inovação Científica, Pedagógica e Tecnológica (Editora da UFRGS, Porto Alegre, 2013).

[5] R. Weber, N. Heinen e L. Kummer, Anos 90 15, 143 (2001/2002)

[6] Universidade do Rio Grande do Sul, Livro de Atas do Conselho Técnico Científico. 1954-1958 (Centro de Pesquisas Físicas, Porto Alegre, 1959).

[7] Universidade do Rio Grande do Sul, Livro de Atas do Conselho Deliberativo. 1953-1959 (Centro de Pesquisas Físicas, Porto Alegre, 1960).

[8] Universidade Federal do Rio Grande do Sul, Relatório da Direção: exercício de 1969 (Centro de Pesquisas Físicas, Porto Alegre, 1970).

[9] Ana Maria Ribeiro de Andrade, Físicos, Mésons e Política: A Dinâmica da Ciência na Sociedade (Hucitec, São Paulo 1999).

[10] O. Guilherme, O Brasil e a Era Atômica (Editorial Vitória, Rio de Janeiro, 1957).

[11] A.M. Fernandes, A Construção da Ciência no Brasil e a $S B P C$ (UNB, Brasília, 1989).

[12] P. Marques, Sofismas Nucleares: O Jogo das Trapaças na Política Nuclear no País (Hucitec, São Paulo, 1992).

[13] Ana Maria Ribeiro de Andrade, A Opção Nuclear: 50 Anos Rumo À Autonomia (MAST, Rio de Janeiro, 2006).

[14] P. Marques, Revista de Economia Política e História Econômica 16, 5 (2009).

[15] A.F. de Freitas e Darcy Dillenburg, Jornal da Universidade, nov./dez., 12 (2003).

[16] C.A. dos Santos, Revista Brasileira de Ensino de Física 35, 1607 (2013) 